\title{
Função hepática e renal de éguas submetidas à inoculação de antígeno botrópico para produção de soro antiofídico
}

Mariana Nahum del Castillo;, Aline Emerim Pinna, Franccesca Silveira Regianini, Mário Felipe Alvarez Balaro, Nadia Regina Pereira Almosny

Universidade Federal Fluminense (UFF), Niterói, RJ, Brasil

*Autor correspondente

e-mail: mariana_nahum@hotmail.com

\section{Resumo}

Acidentes ofídicos têm sido um desafio médico e veterinário. 0 único tratamento disponível e preconizado pela Organização Mundial da Saúde e pelo Ministério da Saúde é a soroterapia. A produção de soro envolve a injeção subcutânea de venenos de crotalídeos em cavalos; embora estas injeções causem, em pequeno percentual dos animais, alterações locais como edema e abcesso, ainda não foram demonstrados alterações sistêmicas. A metabolização do veneno inoculado no cavalo é hepática e sua eliminação renal. São escassos estudos sobre a avaliação das alterações hepática e renal em animais utilizados na produção de antivenenos, principalmente estudos integrando diferentes abordagens para avaliar esses efeitos. A avaliação da preservação desses órgãos é realizada principalmente pelo exame físico, exame ultrassonográfico e laboratorial (hemograma, perfil hepático e renal). 0 objetivo do estudo foi avaliar a função hepática e renal dos equinos submetidos ao protocolo de imunização de base empregado atualmente pelo Instituto Vital Brazil- IVB para produção do soro antibotrópico. Foram utilizadas cinco éguas entre 5 a 15 anos de idade, que não haviam sido inoculadas anteriormente, e alojadas no IVB sob manejo semi-intensivo. A imunização de base consiste em oito inoculações da solução de antígeno, com intervalo de uma semana entre elas. As amostras de sangue das éguas foram coletadas em tubos sem anticoagulante, por punção da veia jugular, em três momentos durante o processo de imunização de base, sendo a primeira amostra coletada previamente ao início da imunização (T1), a segunda coleta na quarta semana (T2) e a terceira no final da imunização (T3). Após a coleta, o sangue foi armazenado e transportado refrigerado para o Laboratório de Pesquisa Clínica e Molecular Marcilio Dias do Nascimento, da Faculdade de Veterinária da Universidade Federal Fluminense. Avaliou-se o perfil hepático pelas enzimas Transaminase Aspartato Aminotransferase (AST), Alanina Transaminase (ALT), GamaglutamilTransferase (GGT), Fosfatase Alcalina e Proteínas totais, albumina e globulinas (calculada pela subtração da albumina na proteína). 0 perfil renal foi avaliado pela 
dosagem de ureia e creatinina. Adotou-se metodologia de espectrofotometria ou cinética, de acordo com normas do fabricante, em aparelho automatizado (Labmax $4000^{\circledR}$, LabTest, São Paulo, Brasil). Utilizouse o programa estatístico Bioestat 5.0 para a análise dos índices bioquímicos. Inicialmente, verificou-se a normalidade dos dados pelo teste de Lilliefors. Na sequência, verificou-se o efeito do tempo (T1, T2, T3) sobre as variáveis pela análise de variância para medidas repetidas e comparação de médias pelo teste de Tukey a 5\% de significância. Os parâmetros da ALT (11,1 $\pm 4,0 \mathrm{U} / \mathrm{L})$, albumina (2,3 \pm 0,3 g/dL) e creatinina $(4,0 \pm 0,2 \mathrm{mg} / \mathrm{dL})$ não apresentaram efeito $(\mathrm{P}>0,05)$ de tempo. Já as variáveis AST $(140 \pm 18,4$ vs 246,2 $\pm 41,7=301,6 \pm 29,7 \mathrm{U} / \mathrm{L}), \mathrm{GGT}(4,6 \pm 1,9$ vs 3,6 $\pm 3,9=13,2 \pm 4,2 \mathrm{U} / \mathrm{L})$, proteínas totais $(7,8 \pm 0,5$ vs 7,33 $\pm 0,4=9,2 \pm 0,4 \mathrm{~g} / \mathrm{dL})$ e globulina $(5,3 \pm 0,5$ vs $4,89 \pm 0,3=7,1 \pm 0,3 \mathrm{~g} / \mathrm{dL})$ apresentaram maiores valores $(\mathrm{P}<0,05)$ no T3 comparados a T1 e T2. A ureia apresentou valor superior em T1 (34 $\pm 3,4$ vs $22 \pm 3,1$ $=26,2 \pm 3,3 \mathrm{mg} / \mathrm{dL})$. Houve uma tendência $(\mathrm{P}=0,07)$ de elevação da FA em T3. 0 aumento da AST pode corroboar lesão nos hepatócitos ou musculares por ação do antígeno inoculado. 0 aumento na GGT indica lesão dos canalículos biliares, redução do fluxo nos canais biliares, provavelmente por causa intra-hepática, devido a inoculação do antígeno ao longo da imunização. Já a proteína total teve seu valor elevado devido ao aumento de síntese de globulinas decorrente do processo de imunização. Os resultados obtidos sugerem que ao longo do período de imunização de base podem ocorrer alterações hepáticas, mas não renais (sobre a metodologia proposta).

Palavras-chave: Soroterapia. Bioquímica. Equinos. 